\title{
Lattice Site Location Studies of Rare-Earths Implanted in ZnO Single-Crystals
}

\author{
Elisabete M.C. Rita ${ }^{1,2}$, Ulrich Wahl ${ }^{1,2}$, Armandina L. Lopes ${ }^{3}$, João P. Araújo ${ }^{4}$, \\ João G. Correia ${ }^{1,2,5}$, Eduardo Alves ${ }^{1,2}$, José C. Soares ${ }^{1,2}$, and the ISOLDE Collaboration ${ }^{5}$ \\ ${ }^{1}$ Instituto Tecnológico e Nuclear, Estrada Nacional 10, PT-2685 Sacavém, Portugal \\ ${ }^{2}$ CFNUL, Av. Prof. Gama Pinto 2, PT-1699 Lisboa Codex, Portugal \\ ${ }^{3}$ Departamento de Física da Universidade de Aveiro, PT-3800 Aveiro, Portugal \\ ${ }^{4}$ IFIMUP, University of Porto, PT-4150 Porto, Portugal \\ ${ }^{5}$ CERN-EP, CH-1211 Geneva 23, Switzerland
}

\begin{abstract}
In this work we report on the lattice site location of rare earths in single-crystalline $\mathrm{ZnO}$ by means of the emission channeling (EC) technique. Following low dose $\left(3 \times 10^{13} \mathrm{at} / \mathrm{cm}^{2}\right) 60 \mathrm{keV}$ ion implantation of the precursor isotope ${ }^{169} \mathrm{Yb}$, a position-sensitive electron detector was used to monitor the angular distribution of the conversion electrons emitted from ${ }^{169} \mathrm{Tm}^{*}$ as a function of the annealing temperature up to $600^{\circ} \mathrm{C}$ in vacuum. An additional annealing at $800^{\circ} \mathrm{C}$ in flowing $\mathrm{O}_{2}$ was performed. The EC measurements revealed that around $95-100 \%$ of the rare earth atoms occupy substitutional $\mathrm{Zn}$ sites up to an annealing temperature of $600^{\circ} \mathrm{C} /$ vacuum. After the $800^{\circ} \mathrm{C} / \mathrm{O}_{2}$ annealing, the emission channeling effects decreased considerably.
\end{abstract}

\section{INTRODUCTION}

Rare earth doped semiconductors exhibit visible or infrared luminescence and are of interest for optoelectronic applications, for instance, as light emitting diodes [1]. Experimental evidence of high luminescence efficiency from rare earths in wide band gap semiconductors [2], such as $\mathrm{GaN}$, pointed out these systems as possible materials for electroluminescent devices. The II-VI compound zinc oxide $(\mathrm{ZnO})$ is one of the materials investigated in that respect. With a band gap of similar width as GaN, this oxide offers the advantage of growing high quality bulk single crystals more easily.

Rare earth doping of $\mathrm{ZnO}$ during growth has already been described previously in the literature [3-10]. However, the production of doped layers by ion implantation, the main doping technique used in semiconductor technology, has not been exploited to a great extent. A fundamental step to understand the doping effects from implanted elements is to learn their lattice location. In the particular case of low concentrations of implanted elements, this can be achieved using the emission channeling (EC) technique, which makes use of the fact that charged particles emitted from radioactive isotopes in single-crystals experience channeling or blocking effects along crystallographic axis and planes.

In this work we report on the lattice location of the rare earth isotope ${ }^{169} \mathrm{Tm}^{*}\left(\mathrm{t}_{1 / 2}=0.66 \mu \mathrm{s}\right)$ in a $\mathrm{ZnO}$ single crystal using emission channeling, following ion implantation of its precursor ${ }^{169} \mathrm{Yb}$ $\left(t_{1 / 2}=32 \mathrm{~d}\right)$. The ${ }^{169} \mathrm{Yb}$ probe nuclei decay by electron capture to the excited state ${ }^{169} \mathrm{Tm}^{*}$, which decays to the ${ }^{169} \mathrm{Tm}$ ground state. The latter transition is accompanied by conversion electron emission, which can be used for EC [11]. Using position-sensitive electron detectors [11] the angular distribution of the conversion electrons is measured and provides information about the emitter $\left({ }^{169} \mathrm{Tm}^{*}\right)$ lattice site. Note that since the recoil energy in the ${ }^{169} \mathrm{Yb} \rightarrow{ }^{169} \mathrm{Tm}{ }^{*}$ nuclear decay is less than $1.1 \mathrm{eV}$, it is most likely that ${ }^{169} \mathrm{Tm}^{*}$ has inherited the ${ }^{169} \mathrm{Yb}$ lattice site [11]. 


\section{EXPERIMENT}

In this study a commercially available $\mathrm{ZnO}$ [0001] single-crystal [12], grown by seeded chemical vapor transport and polished on the $\mathrm{O}$ face, was implanted at room temperature with the radioactive isotope ${ }^{169} \mathrm{Yb}$ up to a dose of $3 \times 10^{13} \mathrm{at} / \mathrm{cm}^{2}$ and $60 \mathrm{keV}$ energy. This was performed at the CERN/ISOLDE facility [13], where pure beams of radioactive elements are produced, providing a large variety of isotopes for EC. In order to minimize the fraction of ${ }^{169} \mathrm{Yb}$ atoms channeled during implantation and provide a well-defined depth profile, a $7^{\circ}$ tilt angle from the crystal surface was applied. The resulting range, straggling and peak concentration of ${ }^{169} \mathrm{Yb}$ atoms, as estimated from TRIM calculations [14], are $166 \AA, 54 \AA$, and $2 \times 10^{19} \mathrm{~cm}^{-3}$, respectively.

The emission channeling patterns of the conversion electrons emitted as a consequence of the ${ }^{169} \mathrm{Yb}$ decay were recorded in vacuum with the position-sensitive detection system described in Ref. [11]. Setting an energy window above $95 \mathrm{keV}$ included the 100, 109, 118, 121, 139, 188, 248 and $298 \mathrm{keV}$ conversion electrons emitted by the ${ }^{169} \mathrm{Tm}^{*}\left(\mathrm{t}_{1 / 2}=0.66 \mu \mathrm{s}\right)$ state but excluded lower energy electrons from short-lived states which are populated within a few ns following the ${ }^{169} \mathrm{Yb}$ decay. The angular distributions were measured around the [0001], [11102], [11101] and [ $\overline{2} 113$ ] directions of the $\mathrm{ZnO}$ crystal in the as-implanted state and after $10 \mathrm{~min}$ in situ vacuum annealing at $300^{\circ} \mathrm{C}$ and $600^{\circ} \mathrm{C}$, andex situ annealing at $800^{\circ} \mathrm{C}$ in flowing $\mathrm{O}_{2}$.

The subsequent evaluation of the $\mathrm{Tm}$ sites in the $\mathrm{ZnO}$ lattice was achieved by fitting the experimental channeling patterns with simulated ones. The ${ }^{169} \mathrm{Tm}^{*}$ theoretical emission channeling patterns were calculated by means of the "many beam" theory of electron diffraction in singlecrystals [15]. To describe the $\mathrm{ZnO}$ crystal structure we applied the following structural model. We used lattice constants of $a=3.2495 \AA$ and $c=5.2069 \AA$ [16] and assumed the Zn-O $c$-axis bond length to be $z=0.375 c$, as in an ideal wurtzite structure. In addition, isotropic root mean square (rms) displacements of $u_{1}(\mathrm{Zn})=0.082 \AA$ and $u_{1}(\mathrm{O})=0.085 \AA$ [17] were applied, which would correspond to Debye temperatures of $T_{\mathrm{D}}(\mathrm{Zn})=320 \mathrm{~K}$ and $T_{\mathrm{D}}(\mathrm{O})=696 \mathrm{~K}$. In the simulations, the angular range of $0^{\circ}-3^{\circ}$ around each of the investigated crystal directions was considered in small steps of $\Delta x=\Delta y=0.05^{\circ}$. In order to quantitatively compare experimental and theoretical patterns, the two-dimensional fitting procedure outlined in Ref. [11] was used. The considered lattice sites were substitutional $\mathrm{Zn}$ sites $\left(\mathrm{S}_{\mathrm{Zn}}\right)$ and substitutional $\mathrm{O}$ sites $\left(\mathrm{S}_{\mathrm{O}}\right)$ with varying root mean square (rms) displacements and a variety of interstitial sites, which are described in detail in Ref. [18].

\section{RESULTS}

The experimental emission channeling pattern for the [0001] direction following the $300^{\circ} \mathrm{C}$ annealing step in vacuum is shown in Fig. 1 (a). The observed channeling effect gives direct evidence of the presence of ${ }^{169} \mathrm{Tm}^{*}$ atoms along the $c$-axis. The best two-fraction fit of the theoretical yields to the experimental data is represented in Fig. 1 (e) and corresponds to $104 \%$ of Tm atoms along the $c$-axis. The Tm rms displacement from the $c$-axis which gave the best fit was $0.12 \AA$ (note that the channeling effect is not sensitive to displacements along the channeling direction). The fitted Tm fraction somewhat exceeds $100 \%$ but this is well within the expected accuracy. For instance, the absolute comparison between experiment and theory requires the measured patterns to be corrected for the influence of backscattered electrons. The typical errors in- 
troduced by this procedure can be around $\sim 10 \%$, and since the correction factors also depend on the angle between sample normal and detector, not all patterns are influenced in the same way.

We would like to point out that all sites located along the $c$-axis would cause an emission channeling pattern similar to the one shown in Fig. 1 (a), among them, for instance, substitutional $\mathrm{S}_{\mathrm{Zn}}$ and $\mathrm{S}_{\mathrm{O}}$ or interstitial $\mathrm{T}$ sites. Therefore, to achieve an unambiguous lattice site location, the information obtained along the [1 1102$],[\overline{1} 101]$ and [ $\overline{2} 113]$ directions was considered as well. The experimental patterns for these directions are shown in Figs. 1 (b), (c) and (d), respectively, for the same $300^{\circ} \mathrm{C}$ annealing step. For each of them good fits to the experimental yields were achieved considering only two fractions for the Tm atoms, namely, substitutional at $\mathrm{Zn}$ sites $\mathrm{S}_{\mathrm{Zn}}$, and at random sites, which are supposed to produce an isotropic emission yield. The best two-fraction fits are displayed in Figs. 1 (f), (g) and (h).

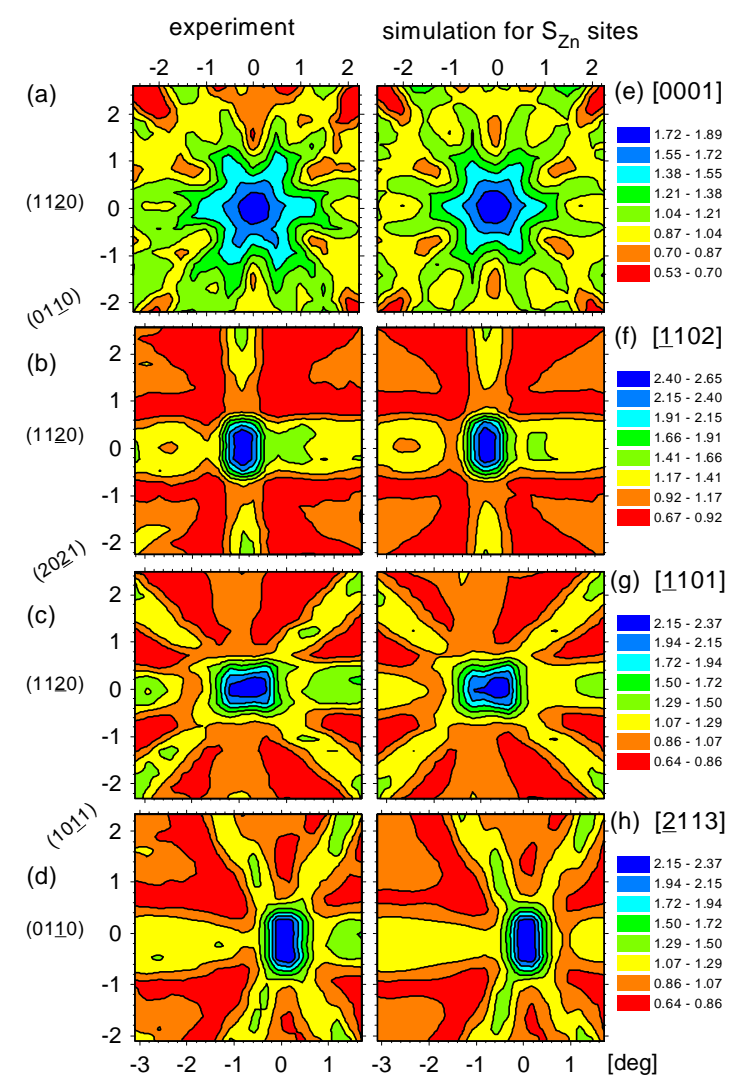

Figure 1. Angular distributions of the ${ }^{169} \mathrm{Tm}^{*}$ conversion electron yields around the [0001] (a), [11102] (b), [1 101] (c) and [ $\overline{2} 113]$ (d) directions following the $300^{\circ} \mathrm{C}$ vacuum annealing. The best fits of the channeling patterns for each direction are also shown and correspond to $104 \%$ (e), $96 \%$ (f), $104 \%(\mathrm{~g})$ and $89 \%(\mathrm{~h})$ of $\mathrm{Tm}$ atoms at $\mathrm{S}_{\mathrm{Zn}}$ sites with rms displacements of $0.12 \AA$, $0.12 \AA, 0.16 \AA$ and $0.15 \AA$, respectively.

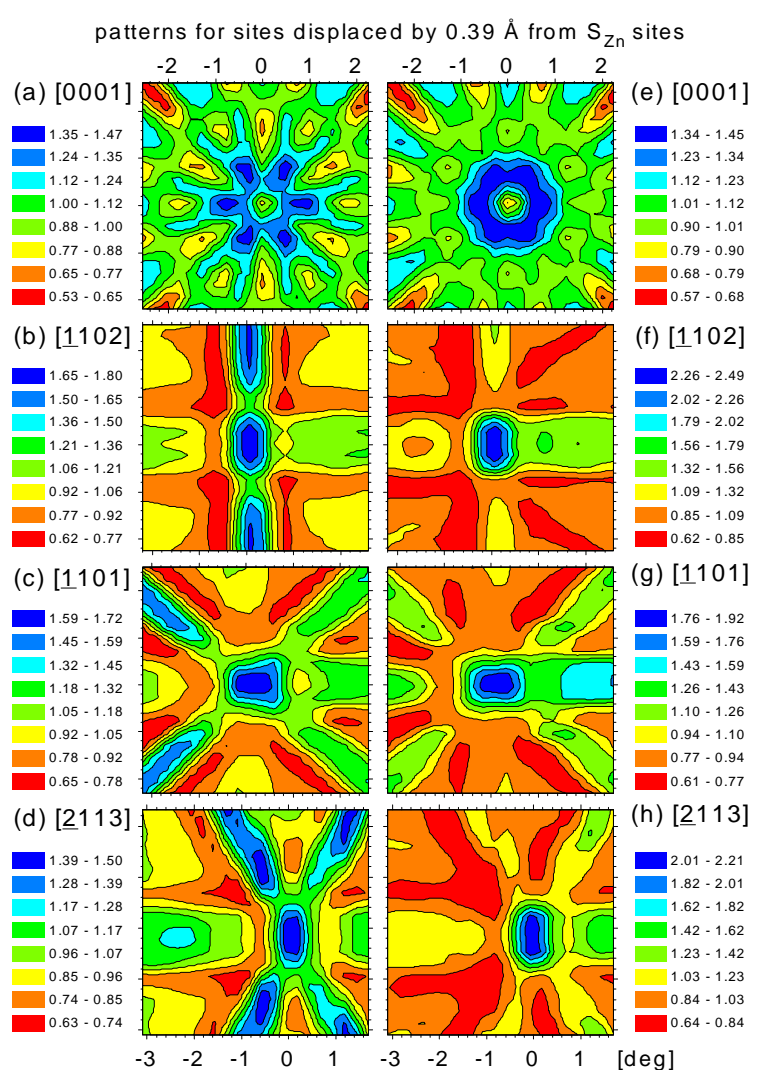

Figure 2. Examples for best fits due to sites which are displaced by $0.39 \AA$ from substitutional $\mathrm{Zn}$ sites, corresponding to $4 / 10$ of the distance towards anti-bonding $(A B)$ or bond center (BC) sites. (a)-(d) are patterns for displacements towards $\mathrm{AB}$ sites off the $c$-axis, while the [0001] pattern (e) is for displacements towards BC sites off the $c$-axis, and the [1102], [1101] and [ $\overline{2} 113]$ patterns (f)-(h) are for displacements to $A B$ sites within the $c$-axis. 
Emission channeling patterns are quite sensitive to displacements of the emitter atoms from ideal substitutional sites. In order to illustrate this, we have displayed in Fig. 2 the fits for patterns resulting from emitter atoms that are displaced by $0.39 \AA$ from ideal $\mathrm{Zn}$ sites towards interstitial sites. Such a displacement already changes the patterns significantly, resulting in chi square of fit values twice larger than those of the fits shown in Fig. 1. We have also tried to fit the experimental patterns by emitter atoms on $\mathrm{S}_{\mathrm{Zn}}$ sites plus additional fractions on substitutional $\mathrm{O}$ or well-defined interstitial sites. However, the chi square of fit did not improve significantly and possible fractions are below $5 \%$. Note that channeling patterns due to emitter atoms on substitutional $\mathrm{O}$ sites $\mathrm{S}_{\mathrm{O}}$ or prominent interstitial sites such as $\mathrm{H}, \mathrm{O}_{\mathrm{i}}$ or $\mathrm{T}$ are distinctively different from those of $S_{Z n}$ sites, as we have shown previously [18-20].

The average fraction of $\mathrm{Tm}$ atoms at $\mathrm{S}_{\mathrm{Zn}}$ sites as a function of the annealing temperature is shown in Fig. 3 (a). We stress that the $800^{\circ} \mathrm{C}$ annealing was performed in flowing $\mathrm{O}_{2}$, while the previous annealings at lower temperatures were in vacuum. As can be seen, annealing the $\mathrm{ZnO}$ single-crystal up to $600^{\circ} \mathrm{C}$ in vacuum did not result in a considerable change of the Tm fraction at $\mathrm{S}_{\mathrm{Zn}}$ sites. The same is not valid for the $800^{\circ} \mathrm{C}$ annealing in flowing $\mathrm{O}_{2}$, after which this fraction decreased from $96 \%$ to $75 \%$.

The room temperature rms displacements of Tm atoms from the perfect $\mathrm{S}_{\mathrm{Zn}}$ sites, perpendicular to the four investigated directions, and observed following the different annealing steps, are displayed in Fig. 3 (b). For all directions, the Tm rms displacements decreased with increasing annealing temperature up to $600^{\circ} \mathrm{C}$ vacuum annealing and increased again after $800^{\circ} \mathrm{C}$ in $\mathrm{O}$. Also, the Tm rms displacements are generally higher than the vibrations of $\mathrm{Zn}$ and $\mathrm{O}$ atoms. However, following the $600^{\circ} \mathrm{C}$ vacuum annealing the $\mathrm{Tm} \mathrm{rms}$ displacements reached values close to the lattice vibrations.

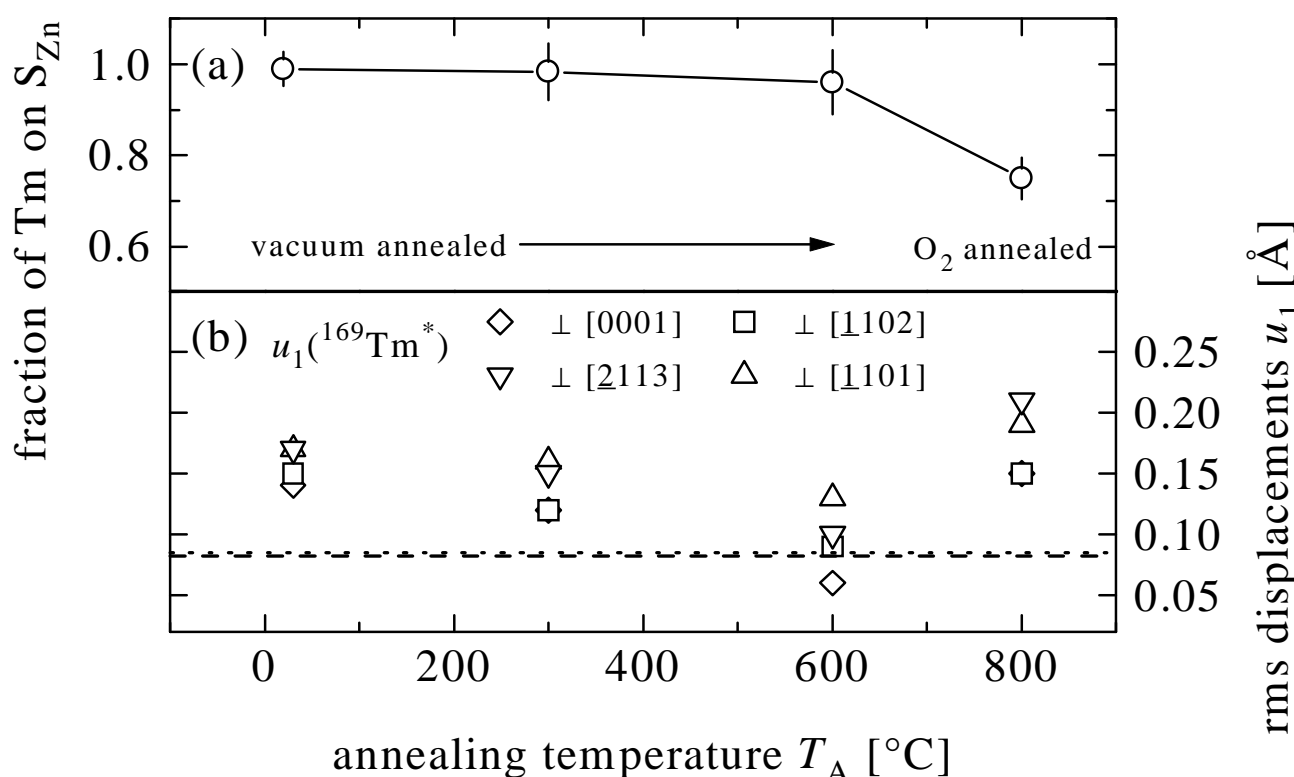

Figure 3. Fraction of $\mathrm{Tm}$ atoms at $\mathrm{S}_{\mathrm{Zn}}$ sites (a) and their rms displacements perpendicular to the [0001], [ $\overline{1} 1102]$, [ 1101$]$ and [ $\overline{2} 113$ ] directions (b) following 10 min annealing steps (in vacuum up to $600^{\circ} \mathrm{C}$ and in flowing $\mathrm{O}_{2}$ at $800^{\circ} \mathrm{C}$ ). The dashed and dotted lines represent the room temperature $\mathrm{Zn}$ and $\mathrm{O}$ vibration amplitudes, respectively. 


\section{DISCUSSION}

The recoil energy of the ${ }^{169} \mathrm{Yb} \rightarrow{ }^{169} \mathrm{Tm}^{*}$ nuclear decay is less than $1.1 \mathrm{eV}$, indicating that the ${ }^{169} \mathrm{Tm}^{*}$ lattice site most probably was inherited from ${ }^{169} \mathrm{Yb}$. Our emission channeling data thus show that already in the as-implanted state around 95-100\% of the rare earth atoms occupy substitutional $\mathrm{Zn}$ sites. The fact that no annealing is needed in order to incorporate the rare earths on substitutional sites is a consequence of both the relatively low dose used in our experiment $\left(3 \times 10^{13} \mathrm{at} / \mathrm{cm}^{2}\right)$ and the high resistance of $\mathrm{ZnO}$ against the formation of structural defects by irradiation. However, the slight decrease in the Tm rms displacement as a function of annealing temperature up to $600^{\circ} \mathrm{C}$ indicates a more perfect incorporation into substitutional $\mathrm{Zn}$ sites. This may be explained by the annealing of some structural defects in the neighborhood of the rare earth atoms and is in fact the only indication of defect annealing we have observed in this experiment.

While annealing in vacuum up to $600^{\circ} \mathrm{C}$ did not change the substitutional Tm fraction, a decrease was observed after the $800^{\circ} \mathrm{C} / \mathrm{O}_{2}$ annealing step, accompanied by an increase of the Tm rms displacement. In principle this behavior could be due, e.g., to a degradation of the $\mathrm{ZnO}$ single-crystal surface during the annealing, which would also introduce disorder in the lattice. However, according to previous experiments which we performed in $\mathrm{ZnO}$ single-crystals implanted with $\mathrm{Er}$ at the higher dose of $5 \times 10^{15} \mathrm{at} / \mathrm{cm}^{2}$ [21], a more likely explanation is the diffusion of the rare earth element itself. In this previous study, Rutherford backscattering (RBS) showed nearly complete damage recovery and no surface degradation after $1050^{\circ} \mathrm{C}$ annealing in air, while only $50 \%$ of the implanted Er atoms remained in the crystal following this procedure and the onset of Er diffusion was already visible following $800^{\circ} \mathrm{C}$ annealing in air.

It is also interesting to compare the present work to our previous emission channeling studies of the lattice location of rare earth ${ }^{167} \mathrm{Tm} /{ }^{167 \mathrm{~m}} \mathrm{Er}$ in $\mathrm{ZnO}$ [20]. A similar behavior was found in terms of lattice site preference, fractions and rms displacements. In fact, up to $700^{\circ} \mathrm{C}$ vacuum annealing $75-90 \%$ of ${ }^{167 \mathrm{~m}} \mathrm{Er}$ atoms were stable at the $\mathrm{S}_{\mathrm{Zn}}$ site and a slight decrease in the Er rms displacement was observed [20]. Also, the $800^{\circ} \mathrm{C}$ annealing step resulted in a decrease of the substitutional Er fraction and an rms displacement increase. Thus the fact that the $800^{\circ} \mathrm{C}$ vacum annealing step in the previous $\mathrm{Tm} / \mathrm{Er}$ experiment was replaced by $800^{\circ} \mathrm{C}$ annealing under flowing $\mathrm{O}_{2}$ in the present $\mathrm{Yb} / \mathrm{Tm}$ study, did not significantly change the experimental outcome.

\section{CONCLUSIONS}

Our emission channeling experiments show that the majority of Tm atoms (95-100\%) are incorporated on substitutional $\mathrm{Zn}$ sites following low dose ion implantation at room temperature. We found no evidence for the presence of Tm atoms in other highly symmetric sites than substitutional $\mathrm{Zn}$ sites. Annealing the sample up to $600^{\circ} \mathrm{C}$ in vacuum did not affect the substitutional Tm fraction, but after the $800^{\circ} \mathrm{C}$ annealing in $\mathrm{O}_{2}$ a considerable decrease of this fraction to $75 \%$ was observed, most likely related to rare earth diffusion. With respect to the rare earth doping of $\mathrm{ZnO}$ by means of ion implantation, the substitutional incorporation of the rare earth atoms seems hence to be a minor problem, while their diffusion poses a severe limit on the subsequent processing temperatures. This may present problems since the restoration of the optical properties of $\mathrm{ZnO}$ following implantation and the optical activation of rare earth dopants generally require annealing at high temperatures [21]. 


\section{ACKNOWLEDGMENTS}

This work was funded by the Fundação para a Ciência e a Tecnologia (FCT), Portugal (project CERN/FIS/43725/2001) and by the European Union (Large Scale Facility contract HPRICT-1999-00018). E. Rita, U. Wahl and J.P. Araújo acknowledge their fellowships supported by the FCT, Portugal.

\section{REFERENCES}

1. T. Gregorkiewicz and J.M. Langer, Mat. Res. Soc. Bull. 24/9, 27 (1999).

2. P.N. Favennec, H. L'Haridon, D. Moutonnet, M. Salvi, and M. Gauneau, Mater. Res. Soc. Symp. Proc. 301, 181 (1993).

3. V.X. Quang, N.Q. Liem, N.C. Thanh, T.V. Chuong, and L.T. Le Thanh, Phys. Stat. Sol. 78, K161 (1983).

4. S. Bachir, K.Azuma, J. Kossanyi, P. Valat, and J.C. Ronfard-Haret, J. Lumin. 75, 35 (1997).

5. Y.K. Park, J.I. Han, M.G. Kwak, H. Yang, S.H. Ju, and W.S. Cho, Appl. Phys. Lett. 72, 668 (1998).

6. N. Mais, J.P. Reithmaier, A. Forchel, M. Kohls, L. Spanhel, and G. Müller, Appl. Phys. Lett. 75, 2005 (1999).

7. S. Komuro, T. Katsumata, T. Morikawa, X. Zhao, H. Isshiki, and Y. Aoyagi, Appl. Phys. Lett. 76, 3935 (2000).

8. S. Komuro, T. Katsumata, T. Morikawa, X. Zhao, H. Isshiki, and Y. Aoyagi, J. Appl. Phys. 88, 7129 (2000).

9. X. Zhao, S. Komuro, Y. Aoyagi, and T. Sugano, J. Lumin. 87-89, 1254 (2000).

10. S.M. Liu, F.Q. Liu, and Z.G. Wang, Chem. Phys. Lett. 343, 489 (2001).

11. U. Wahl, J.G. Correia, S. Cardoso, J.G. Marques, A. Vantomme, G. Langouche, and the ISOLDE collaboration, Nucl. Instrum. Meth. B 136-138, 744-750 (1998).

12. Purchased from Eagle-Picher Technologies, Miami, OK 74354.

13. E. Kugler, D. Fiander, B. Jonson, H. Haas, A. Przewloka, H. L. Ravn, D. J. Simon, K. Zimmer, and the ISOLDE collaboration, Nucl. Instrum. Meth. Phys. Res. B 70, 41 (1992).

14. J.F. Ziegler and J.P. Biersack, The Stopping and Range of Ions in Matter (Pergamon Press, New York, 1985).

15. H. Hofsäss and G. Lindner, Phys. Rep. 210, 121 (1991).

16. U. Rössler, in Landolt-Börnstein New Series, Vol. 22, edited by O. Madelung (Springer, Berlin, 1989), p. 163.

17. H. Schulz and K.H. Thiemann, Solid State Comm. 32, 783 (1979).

18. U. Wahl, A. Vantomme, G. Langouche, J.P. Araújo, J.G. Correia, L. Peralta, and the ISOLDE collaboration, J. Appl. Phys. 88, 1319 (2000).

19. U. Wahl, A. Vantomme, G. Langouche, J.G. Correia, L. Peralta, and the ISOLDE collaboration, Appl. Phys. Lett. 78, 3217 (2001).

20. U. Wahl, E. Rita, J.G. Correia, E. Alves, J.P. Araújo and the ISOLDE collaboration, Appl. Phys. Lett. (in press).

21. E. Alves, E. Rita, U. Wahl, J.G. Correia, T. Monteiro, and C. Boemare, Nucl. Instrum. Meth. Phys. Res. B (in press). 